\title{
Complementary Interactions between Command-Like Interneurons that Function to Activate and Specify Motor Programs
}

\author{
Jin-Sheng Wu ${ }^{1 \star}$ Nan Wang, ${ }^{2 \star}$ Michael J. Siniscalchi, ${ }^{1 \star}$ Matthew H. Perkins, ${ }^{1}$ Yu-Tong Zheng, ${ }^{2}$ Wei Yu, ${ }^{2}$ Song-an Chen, ${ }^{2}$ \\ Ruo-nan Jia, ${ }^{2}$ Jia-Wei Gu, ${ }^{2}$ Yi-Qing Qian, ${ }^{2}$ Yang Ye, ${ }^{2}$ Ferdinand S. Vilim, ${ }^{1}$ Elizabeth C. Cropper, ${ }^{1}$ Klaudiusz R. Weiss, ${ }^{1}$ \\ and Jian Jing ${ }^{1,2}$ \\ ${ }^{1}$ Department of Neuroscience and Friedman Brain Institute, Mount Sinai School of Medicine, New York, New York 10029, and ${ }^{2}$ State Key Laboratory of \\ Pharmaceutical Biotechnology, School of Life Sciences, Nanjing University, Jiangsu 210093, China
}

\begin{abstract}
Motor activity is often initiated by a population of command-like interneurons. Command-like interneurons that reliably drive programs have received the most attention, so little is known about how less reliable command-like interneurons may contribute to program generation. We study two electrically coupled interneurons, cerebral-buccal interneuron-2 (CBI-2) and CBI-11, which activate feeding motor programs in the mollusk Aplysia californica. Earlier work indicated that, in rested preparations, CBI-2, a powerful activator of programs, can trigger ingestive and egestive programs. CBI-2 reliably generated ingestive patterns only when it was repeatedly stimulated. The ability of CBI-2 to trigger motor activity has been attributed to the two program-promoting peptides it contains, FCAP and CP2. Here, we show that CBI-11 differs from CBI-2 in that it contains FCAP but not CP2. Furthermore, it is weak in its ability to drive programs. On its own, CBI-11 is therefore less effective as a program activator. When it is successful, however, CBI-11 is an effective specifier of motor activity; that is, it drives mostly ingestive programs. Importantly, we found that CBI-2 and CBI-11 complement each other's actions. First, prestimulation of CBI-2 enhanced the ability of CBI-11 to drive programs. This effect appears to be partly mediated by CP2. Second, coactivation of CBI-11 with CBI-2 makes CBI-2 programs immediately ingestive. This effect may be mediated by specific actions that CBI-11 exerts on pattern-generating interneurons. Therefore, different classes of command-like neurons in a motor network may make distinct, but potentially complementary, contributions as either activators or specifiers of motor activity.
\end{abstract}

Key words: Aplysia; central pattern generator; command neurons; electrical coupling; feeding; population coding

\section{Introduction}

Command-like interneurons are activated by appropriate inputs and in turn drive pattern-generating circuits to produce complex outputs (Wiersma and Ikeda, 1964; Kupfermann and Weiss, 1978; Jing, 2009). These neurons have recently attracted a renewed interest because of the discovery of a command-like neuron in the feeding circuit of a genetic organism, Drosophila (Flood et al., 2013).

Initially, single command-like neurons were thought to drive single behaviors (Wiersma and Ikeda, 1964; Frost and Katz, 1996; Edwards et al., 1999; Jing and Gillette, 1999; Eaton et al., 2001;

Received Dec. 4, 2013; revised March 13, 2014; accepted March 31, 2014.

Author contributions: J.-S.W., K.R.W., and J.J. designed research; J.-S.W., N.W., M.J.S., M.H.P., J.-W.G., and J.J. performed research; F.S.V. contributed unpublished reagents/analytic tools; J.-S.W., N.W., M.J.S., M.H.P., Y.-T.Z., W.Y., S.C., R.J., Y.-Q.Q., Y.Y., and J.J. analyzed data; E.C.C., K.R.W., and J.J. wrote the paper.

This work was supported by the National Institutes of Health (Grants NSO66587, NS070583, and MH051393), the National Natural Science Foundation of China (Grant 31371104), and the National Undergraduate Innovation Program and National Natural Science Foundation of China (Grants J1103512 and J1210026).

The authors declare no competing financial interests.

*J.-S.W., N.W., and M.J.S. contributed equally to this work.

Correspondence should be addressed to Jian Jing, PhD, School of Life Sciences, Nanjing University, Jiangsu 210093, China. E-mail:jingj01@gmail.com.

DOI:10.1523/JNEUROSCI.5094-13.2014

Copyright $\odot 2014$ the authors $\quad 0270-6474 / 14 / 346510-12 \$ 15.00 / 0$
Korn and Faber, 2005). However, more recent work showed that pattern-generating networks activated by command neurons are often multifunctional; that is, they generate multiple types of motor programs (Nusbaum and Beenhakker, 2002; Jing and Weiss, 2005; Marder and Bucher, 2007; Briggman and Kristan, 2008; Benjamin, 2012). Therefore, to initiate behavior, it does not suffice to simply trigger activity in the motor network-the type of program induced must also be specified. The question, then, is whether command neurons themselves subserve both functions, meaning do they both activate programs and specify their nature? Croll et al. (1985) provided a positive answer; they applied the simple command neuron concept to multifunctional networks by suggesting that specialized command-like neurons drive and specify different behaviors. However, research on other multifunctional networks questions the generality of this scheme. Under different circumstances, one neuron drives different behaviors in cricket, leech, and Aplysia (Nolen and Hoy, 1984; Jing and Weiss, 2001; Esch et al., 2002; Morgan et al., 2002; Jing et al., 2004). Therefore, the latter studies suggest that command-like neurons, especially those that drive programs reliably, may function preferentially to trigger programs, rather than to specify their nature. Here, we provide evidence suggesting that command neuron function may be more complex. Moreover, this study differs 
from previous research that has focused on command-like neurons that reliably trigger motor activity (Nolen and Hoy, 1984; Edwards et al., 1999; Eaton et al., 2001; Esch et al., 2002; Morgan et al., 2002; Flood et al., 2013). Not all command-like neurons fall into this category, so the functional contribution of this type of neuron is largely uncharacterized. We ask, could these less reliable command-like neurons play a role in specifying the nature of programs?

Here, we characterize an Aplysia feeding command-like neuron, CBI-11, that is weak in its ability to drive programs. We contrast CBI-11 with CBI-2 that is electrically coupled with CBI11. Although CBI-2 is activated by food and reliably triggers motor activity, when it is stimulated in rested preparations, evoked programs can be of different types. It is only with repeated stimulation that CBI-2 induces ingestive activity. We show that CBI-11 differs in that programs are immediately ingestive, both when CBI-11 is activated on its own and when CBI-11 and CBI-2 are coactivated. CBI-11 therefore acts as an immediate specifier of program nature. Finally, prestimulation of CBI-2 enhances the ability of CBI-11 to drive programs through a peptidergic mechanism. We discuss the implications of our work for conceptualization of command functions, the classification of interneurons, and neural coding.

\section{Materials and Methods}

Subjects. Experiments were performed on Aplysia californica (100-250 g) obtained from Marinus. Aplysia are hermaphroditic (i.e., each animal has reproductive organs normally associated with both male and female sexes).

Antibodies and immunostaining. CP2 antibody (rabbit) was a gift from Dr. P. Lloyd (Phares and Lloyd, 1996). FCAPb (ALDSLGGFQVHGW, ALDSLGGFQVHGW; Protein Core Facility, University of Illinois, Urbana, IL) was used to generate the antibodies in rabbits as described previously (Furukawa et al., 2001; Jing et al., 2010). Briefly, the antigen was prepared by coupling synthetic peptide to BSA (catalog \#A0281; Sigma-Aldrich) using 1-ethyl-3-(dimethylaminopropyl)carbodiimide (catalog \#E7750; Sigma-Aldrich). The coupled antigen was purified and used to inoculate the rabbits. Testing of the rabbit FCAP antibodies showed that immunostaining was abolished by preincubation with $10^{-4} \mathrm{M}$ ALDSLGGFQVHGW (data not shown).

Immunocytochemistry combined with dye injection was performed as described previously (Furukawa et al., 2001; Jing et al., 2010). CBI-11 was identified based on morphology and electrophysiological characteristics (Wu et al., 2003) and injected with carboxyfluorescein (Jing et al., 2003). Tissues were then fixed in freshly prepared fixative (4\% paraformaldehyde, $0.2 \%$ picric acid, $25 \%$ sucrose, and $0.1 \mathrm{M} \mathrm{NaH}_{2} \mathrm{PO}_{4}, \mathrm{pH}$ 7.6). Tissue was permeabilized and blocked by overnight incubation in blocking buffer $(10 \%$ normal donkey serum, $2 \%$ Triton X-100, 1\% BSA, $154 \mathrm{~mm}$ $\mathrm{NaCl}, 50 \mathrm{~mm}$ EDTA, $0.01 \%$ thimerosal, and $10 \mathrm{~mm} \mathrm{Na}_{2} \mathrm{HPO}_{4}$, $\mathrm{pH}$ 7.4). The primary antibody was diluted 1:250 in the blocking buffer and incubated with the tissue for $4-7 \mathrm{~d}$. The tissue was then washed twice per day for $2-3 \mathrm{~d}$ with washing buffer ( $2 \%$ Triton X-100, $1 \% \mathrm{BSA}, 154 \mathrm{~mm} \mathrm{NaCl}$, $50 \mathrm{~mm}$ EDTA, $0.01 \%$ thimerosal, and $10 \mathrm{~mm} \mathrm{Na}_{2} \mathrm{HPO}_{4}$, pH 7.4). After the washes, the tissue was incubated with a 1:500 dilution of secondary antibody (lissamine rhodamine donkey anti-rabbit; Jackson ImmunoResearch) for 2-3 d. The tissue was then washed twice with the washing buffer for $1 \mathrm{~d}$ and four times with storage buffer (1\% BSA, $154 \mathrm{~mm}$ $\mathrm{NaCl}, 50 \mathrm{~mm}$ EDTA, $0.01 \%$ thimerosal, and $10 \mathrm{~mm} \mathrm{Na}_{2} \mathrm{HPO}_{4}, \mathrm{pH} 7.4$ ) for $1 \mathrm{~d}$. The preparations were viewed and photographed with either a Nikon or an Olympus BX43 fluorescence microscope equipped with the appropriate filters.

Electrophysiology. Animals were anesthetized by injection of isotonic $\mathrm{MgCl}_{2}$ (337 mM; 30-50\% of body weight). All experimental preparations were bathed in artificial seawater (ASW). The composition of normal ASW was as follows (in mM): $460 \mathrm{NaCl}, 10 \mathrm{KCl}, 11 \mathrm{CaCl}_{2}, 55 \mathrm{MgCl}_{2}$, and 10 HEPES, pH 7.6. To suppress polysynaptic pathways, a high-divalent
(HiDi) cation saline was used containing the following (in $\mathrm{mm}$ ): 368 $\mathrm{NaCl}, 8 \mathrm{KCl}, 13.8 \mathrm{CaCl}_{2}, 115 \mathrm{MgCl}_{2}$, and $10 \mathrm{HEPES}, \mathrm{pH}$ 7.6. All reagents were obtained from Sigma.

Two types of preparations were used. For Figure $1 B$, a semi-intact preparation (Jing and Weiss, 2005) was prepared by excising the head and buccal mass with cerebral and buccal innervation intact. The head and buccal mass were placed in a larger chamber, and the cerebral ganglion was pinned in a smaller chamber and desheathed locally to expose CBIs. The buccal artery was canulated to allow perfusion of the buccal mass with ASW. Feeding behavior was elicited by touching the mouth with cut pieces of dried seaweed $(\sim 3.5 \times 24 \mathrm{~mm})$ held by forceps. A typical feeding sequence consisted of initial biting responses and late swallowing responses that were initiated if the seaweed was successfully grasped. Completion of swallowing was verified by the visual observation of the seaweed moving out of the cut end of the esophagus.

The remainder of the electrophysiological data, all experiments other than the one shown in Figure $1 B$, were obtained using isolated CNS preparations. The cerebral and buccal ganglia were removed, desheathed (ventral surface of the cerebral ganglion, caudal surface of the buccal ganglion), and pinned in a recording chamber $\left(14-17^{\circ} \mathrm{C}\right.$; volume, $\sim 1$ $\mathrm{ml}$ ) perfused with ASW at $0.33 \mathrm{ml} / \mathrm{min}$.

Initially, intracellular recordings were made using single-barrel electrodes $(5-10 \mathrm{M} \Omega$ ) filled with $2 \mathrm{M} \mathrm{K}$-acetate and $30 \mathrm{~mm} \mathrm{KCl}$. Later experiments used electrodes (5-10 M $\Omega$ ) filled with $0.6 \mathrm{M} \mathrm{K}_{2} \mathrm{SO}_{4}$ and $60 \mathrm{~mm}$ $\mathrm{KCl}$. Intracellular signals were acquired using an AxoClamp 2B amplifier (MDS Analytical Technologies) or a Getting model 5A amplifier. Extracellular signals were acquired from polyethylene suction electrodes using a differential alternating current amplifier (model 1700; A-M Systems). A Grass model S88 stimulator was used for stimulation. In addition to CBI-11 (Wu et al., 2003), all other neurons were identified as described previously (Rosen et al., 1991; Hurwitz et al., 1994; Hurwitz and Susswein, 1996; Jing and Weiss, 2001, 2002; Sasaki et al., 2009).

Motor programs. Each cycle of Aplysia feeding motor programs consists of two phases: a radula protraction phase, followed by a radula retraction phase (Fig. 1C,D1). In this study, motor programs were elicited via intracellular stimulation of higher-order neurons, cerebral-buccal interneuron-2 (CBI-2; Rosen et al., 1991; Jing and Weiss, 2001) and CBI-11 (Wu et al., 2003) at 5-10 and 6-18 Hz, respectively. Each current pulse was set to trigger a single action potential. Stimulation of CBIs was manually terminated after the protraction phase ended as determined by activity in the I 2 nerve.

The buccal central pattern-generator (CPG) circuit generates several types of motor programs. The major components of these programs are protraction-retraction and opening-closing movements of the radula. Regardless of the type of motor program, the phasing of the protractionretraction sequence remains constant. Protraction was monitored by recording from the $\mathrm{I} 2$ nerve, which contains the axons of protractor motor neurons B31/32 and B61/62 (Hurwitz et al., 1994). In some experiments, retraction was monitored by recording from retraction interneuron B64 (Hurwitz and Susswein, 1996). In other experiments, retraction was monitored by the sustained depolarization of the radula closing motor neuron B8 after protraction. In contrast to the phase invariance of the protraction-retraction sequence, the timing of radula opening-closing depends on the type of program (Morton and Chiel, 1993a, 1993b; Church and Lloyd, 1994; Nargeot et al., 1997; Jing and Weiss, 2001; Morgan et al., 2002; Jing et al., 2010; Wu et al., 2010). Briefly, when B8 fires predominantly during retraction and thus (in the intact animal) helps bring food into the buccal cavity, the program is considered to be ingestive. When $\mathrm{B} 8$ fires predominantly during protraction and thus helps in removing an inedible object from the buccal cavity, the program is considered to be egestive. When B8 fires during both protraction and retraction, the program is defined as intermediate.

Data analysis. Electrophysiological recordings were digitized online with Axoscope and plotted with CorelDraw. When calculating average burst frequency of B61 upon 3 min stimulation of CBI-2 or CBI-11, we included B61 bursts with at least 3 spikes. For B64 excitability measurements, the $3 \mathrm{~s}$ current pulses applied to B64 induced plateau potentials that extended B64 firing beyond the $3 \mathrm{~s}$ current pulses in $30 \%$ of tests in 4 preparations; however, for the data to be comparable, we only counted 
A

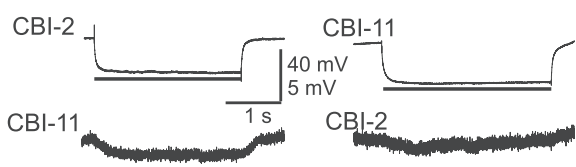

C1

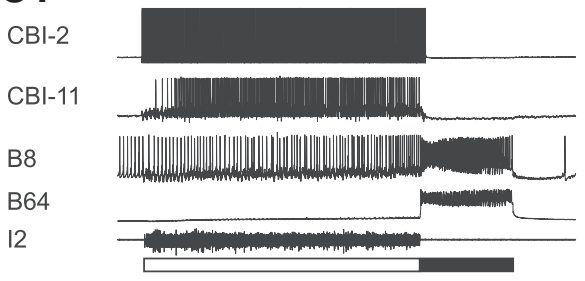

B

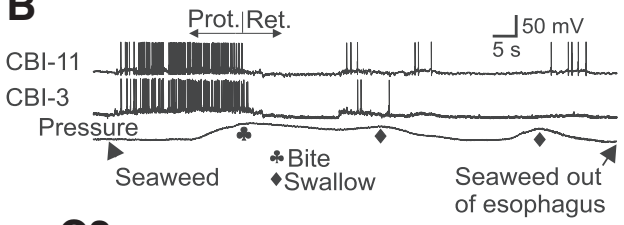

C2

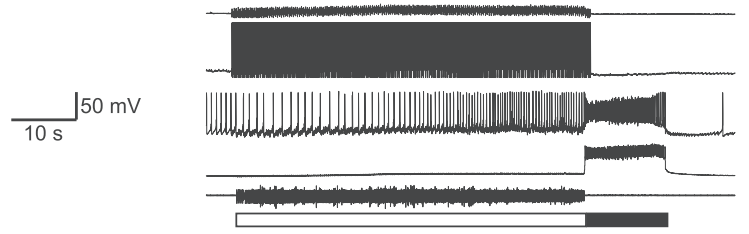

D1

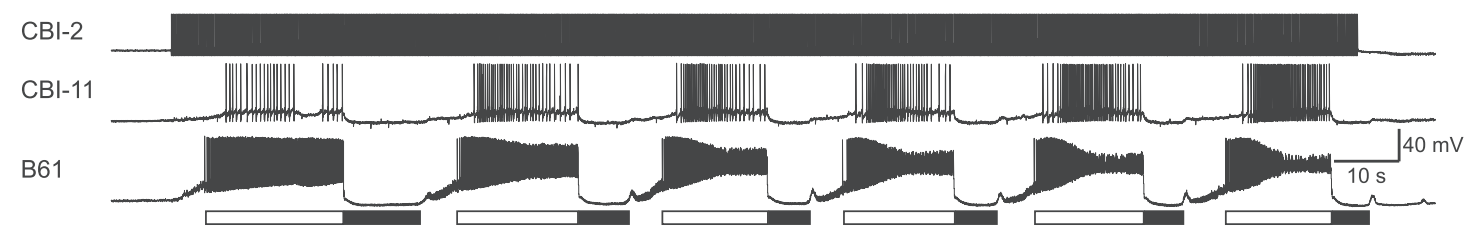

D2

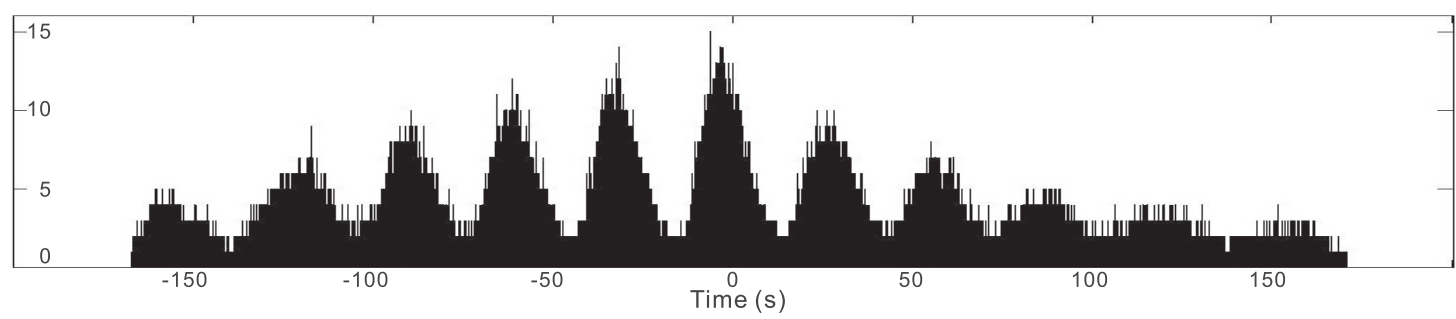

Figure 1. Functional properties and interactions of $\mathrm{CBI}-11$ and $\mathrm{CBI}-2 . \mathrm{A}, \mathrm{CBI}-11$ and $\mathrm{CBI}-2$ are electrically coupled. Negative currents injected into either $\mathrm{CBI}-2$ or $\mathrm{CBI}-11$ (bars) induce hyperpolarization in the other $\mathrm{CBI}$. The electrical coupling appears to be stronger from CBI-2 to CBI-11 than from CBI-11 to CBI-2. $\boldsymbol{B}$, In a semi-intact preparation, dual recordings of CBI-11 and CBI-3 show that they are activated by food stimuli during the protraction (Prot) phase of biting. Ret, Retraction. C, In an isolated CNS preparation, stimulation of either (BI-2 (C1) or CBI-11 (C2) with short current pulses evokes a single cycle of ingestive motor program in which radula closure B8 is weakly active during the protraction phase (monitored by $\mathrm{I} 2$ nerve activity, open bar) but strongly active during the retraction phase (monitored by retraction interneuron B64 activity, filled bar). CBI-11 is recruited into (BI-2-elicited program (C1), but CBI-2 is not recruited into CBI-11-elicited program (C2). D, Continuous stimulation of CBI-2 for 3 min (D1) evokes six cycles of motor programs and (BI-11 is recruited to fire during protraction (monitored by protraction motor neuron B61). CBI-11 exhibits progressively higher activity as more cycles are elicited. D2, Cross-correlogram of spike timing of CBI-11 and B61 in D1 shows that CBI-11 and B61 fired together in bursts, but B61 bursts preceded CBI-11 bursts by $\sim 4 \mathrm{~s}$.

number of spikes during the $3 \mathrm{~s}$ current pulses. Bar graphs were plotted using SigmaPlot. Data are expressed as mean \pm SEM. Statistical tests, which included Student's $t$ test and repeated-measures one-way ANOVA, were applied as appropriate using Prism software (GraphPad). Data that showed significant effects in ANOVA were further analyzed in individual comparisons with Bonferroni's correction. In all statistical tests, effects were considered statistically significant when $p<0.05$.

To generate a cross-correlogram from the two intracellular recordings, each data point of the digitized data (sampling rate of $5 \mathrm{kHz}$ ) was converted into 0 unless at the peak of a spike, in which case, the data point was converted into 1 . The two new data arrays were then used to perform a cross-correlation using MATLAB.

\section{Results}

Higher order interneurons CBI-11 and CBI-2

The cerebral-buccal interneurons in Aplysia are a population of $\sim 13$ neurons (Xin et al., 1999) that have their cell bodies in the cerebral ganglion but send axons to the buccal ganglion, the locus of the feeding CPG. The CBIs are higher-order neurons because they activate and/or modulate feeding motor programs by providing synaptic inputs to specific CPG interneurons in the buccal ganglion. A feature that these neurons share with each other and with higher-order neurons in many other motor networks is that they contain one or more neuropeptides that mediate critical aspects of their functions (Jing and Weiss, 2001; Morgan et al., 2002; Nusbaum and Beenhakker, 2002; Sweedler et al., 2002; Koh et al., 2003; Friedman and Weiss, 2010). In Aplysia, peptides are present in identifiable neurons, facilitating efforts to determine how distinct peptidergic biochemical profiles give rise to unique neural functions.

In this report, we study two functionally related CBIs, CBI-11 (Wu et al., 2003) and CBI-2. The two are ipsilaterally electrically coupled (coupling ratios: from CBI-11 to CBI-2, $0.038 \pm 0.004$; from CBI-2 to CBI-11, $0.073 \pm 0.015, n=6$; Fig. $1 A$ ). Previously (Jing and Weiss, 2005), we demonstrated that CBI-2 is active during feeding in semi-intact preparations; that is, in preparations in which the feeding apparatus (the buccal mass) and head sensory structure were isolated together with the CNS. We performed similar experiments and found that CBI-11 was active during biting responses $(n=3$; Fig. $1 B)$, but was inactive during the subsequent swallowing that occurred when animals successfully grasped the seaweed. We also included a simultaneous recording of CBI-3, which is known to be active during the protraction phase of motor programs (Rosen et al., 1991; Jing and 
Weiss, 2001; Morgan et al., 2002). The CBI-11 firing frequency during the protraction phase of biting responses was $6.9 \pm 1.4 \mathrm{~Hz}$ (range $3.4-10.8 \mathrm{~Hz}, n=5$ ), whereas the CBI-3 firing frequency was $5.8 \pm 1.0 \mathrm{~Hz}$ (range $3.3-9.6 \mathrm{~Hz}, n=6$ ). This activity pattern of CBI-11 and CBI-3 is similar to that exhibited by CBI-2 (Jing and Weiss, 2005). These data are consistent with the idea that CBI-2 and CBI-11 are functionally related.

Previous work showed that both CBI-2 (Rosen et al., 1991; Hurwitz et al., 1997; Jing and Weiss, 2001; Morgan et al., 2002; Hurwitz et al., 2003) and CBI-11 (Wu et al., 2003, their Figure 3) are capable of driving motor programs. This provides us with a means to determine whether the electrical coupling between the two cells affects their activity during programs. We analyzed data from the 10 preparations in which we had dual CBI-2/CBI-11 recordings. We analyzed 113 cycles of activity elicited by CBI-2. In 55 cycles, CBI- 11 did not fire or fired at $<1 \mathrm{~Hz}$; in 39 cycles, CBI- 11 fired between 1 and $2.5 \mathrm{~Hz}$; and in 19 cycles, CBI- 11 fired at $>2.5 \mathrm{~Hz}$ (Fig. 1C1). We analyzed 89 cycles elicited by CBI-11. CBI-2 never fired (Fig. 1C2). These results are expected given the stronger coupling from CBI-2 to CBI- 11 .

In addition, we observed that, when CBI-2 was stimulated and CBI-11 did fire, CBI-11 firing appeared to coincide with the occurrence of the protraction phase of the motor program. During protraction, molluscan CBIs receive excitatory feedback (Gillette et al., 1978; Rosen et al., 1991). This positive feedback could act in conjunction with the electrical coupling to promote CBI-11 activity. To determine more formally the phase at which CBI-11 is activated, we stimulated CBI-2 continuously for 3 min to induce multiple cycles of programs (Fig. 1D1). We then performed a cross-correlation of spike timing of CBI-11 with the radula protraction motor neuron B61. Multiple peaks in the cross-correlogram (Fig. 1D2) demonstrated that CBI-11 and B61 fired together in bursts, but B61 bursting activity preceded CBI-11 activity by $\sim 4 \mathrm{~s}$, because the largest peak is at $\sim-4 \mathrm{~s}$. Therefore, although the coupling between CBI-2 and CBI-11 is relatively weak, CBI-2 appears to be capable of driving CBI-11 during protraction, when there is excitatory feedback to the CBIs from the buccal CPG.

Previous work also showed that CBI-2 contains the motorprogram-inducing neuropeptide FCAP (Sweedler et al., 2002; Koh et al., 2003). CBI-11 is also capable of inducing programs (Wu et al., 2003), which suggests that it might also contain FCAP. Consistent with this idea, previous CBC backfill experiments (Sweedler et al., 2002) located an FCAP-immunoreactive CBI in the region medial to the upper labial nerve. Based on its location, this cell could be CBI- 11 . To determine whether CBI- 11 contains FCAP, we identified it physiologically, injected it with carboxyfluorescein (Fig. 2A1), and then performed FCAP immunocytochemistry $(n=4)$. CBI-11 was immunopositive (Fig. 2A2), suggesting that $\mathrm{CBI}-2$ and $\mathrm{CBI}-11$ are functionally similar in that both are command-like neurons containing FCAP.

Next, we sought to determine the extent to which the transmitter phenotypes of CBI-2 and CBI-11 are similar. This is an important question, because previous work has shown that $\mathrm{CP} 2$ is present in CBI-2 and is critical for its function (Morgan et al., 2000). We performed immunocytochemistry experiments to address this question $(n=3)$. Figure $2 B$ shows one such experiment in which a physiologically identified CBI-11 was injected with carboxyfluorescein (Fig. 2B1) and then processed for immunocytochemistry (Fig. 2B2). CBI-11 was not immunoreactive to $\mathrm{CP} 2$. Therefore, our data suggest that, although in some respects they are functionally similar, CBI-2 and CBI-11 do not contain the same complement of peptide modulators. These findings provide us with an opportunity to determine how distinct pep-
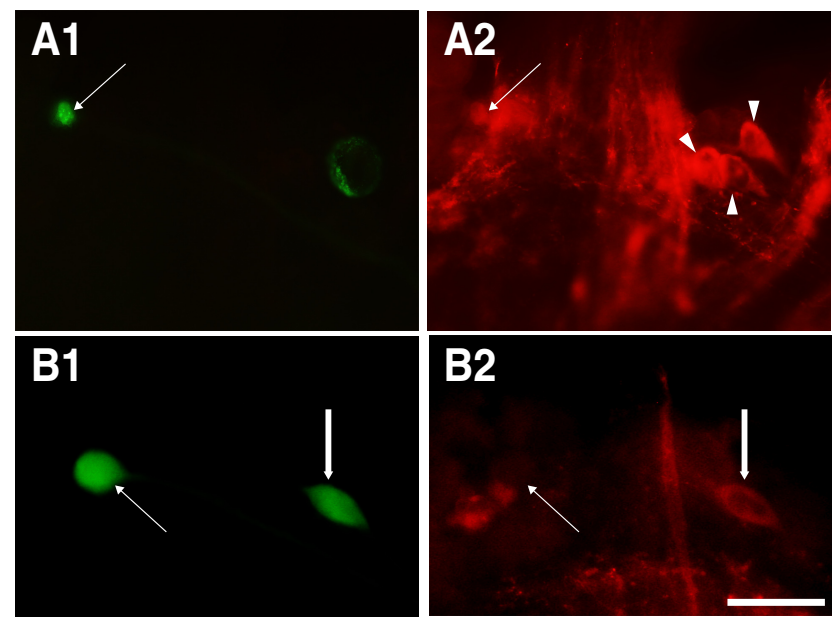

Figure 2. Immunocytochemistry of $\mathrm{CBI}-11 . A, \mathrm{CBI}-11$ (arrows) is immunoreactive to FCAP Arrowheads from left to right in $A 2$ point to $C B I-2, C B I-12$, and $C B \mid-1$, respectively, which are also immunoreactive to FCAP. $B, C B I-11$ (arrows) is not immunoreactive to $C P 2$, but $C B 1-2$ (thick arrows) is. Scale bars: $\boldsymbol{A}, 250 \mu \mathrm{m} ; \boldsymbol{B}, 100 \mu \mathrm{m}$.

tide complements contribute to functional differences between command-like neurons.

\section{Command-like interneurons CBI-11 and CBI-2: motor program generation}

Although both CBI-2 and CBI-11 can induce motor programs when stimulated intracellularly, CBI-11 is less effective than CBI-2. This is reflected in two ways. First, CBI-11 must be stimulated at a higher frequency to drive a motor program and 47 out of 143 programs elicited by CBI- 11 were incomplete (i.e., missing a retraction phase). The threshold frequency for CBI-11 to drive incomplete cycles of programs was, on average, $8.5 \pm 0.5 \mathrm{~Hz}(n=8)$, whereas the threshold frequency to drive full-cycle programs averaged $9.5 \pm 0.3 \mathrm{~Hz}(n=8)$. Note that these frequencies are somewhat higher than the CBI-11 firing frequency observed in semi-intact preparations. However, in these experiments, we are only stimulating a single CBI-11, whereas in semi-intact preparations, both CBI-11s would be activated by food. In contrast, the threshold frequency for CBI-2 to drive full-cycle programs was, on average, $5.3 \pm 0.2 \mathrm{~Hz}(n=7)$, which is statistically different from even the lower value for CBI-11 (i.e., the threshold frequency for CBI-11 to drive incomplete programs; unpaired $t$ test, $p<0.0001, t=5.7)$.

Second, the latency to initiation of the protraction phase of full-cycle programs elicited by repeated stimulation of CBI-11 was long and variable. In contrast, program articulation has been shown to progressively improve with repeated CBI-2 stimulation (Proekt et al., 2004, 2007; Friedman and Weiss, 2010; Dacks et al., 2012). Under these conditions, both FCAP and CP2 are released (Koh and Weiss, 2005) and persistently enhance program generation by the buccal CPG. Therefore, the ingestive character of programs evoked later in a series is stronger despite the fact that CBI-2 stimulation parameters remain constant throughout the series. In addition, the latency to initiation of protraction becomes shorter (Koh et al., 2003).

This persistent effect of CBI-2 stimulation suggests that CBI-2 promotes its own ability to induce programs. We therefore hypothesized that CBI-2 might also influence the ability of other command-like neurons such as CBI-11 to induce programs. To test this hypothesis, we first stimulated CBI-11 2-5 times at 8-10 $\mathrm{Hz}$ for $3 \mathrm{~min}$ to characterize the baseline CPG activity evoked by 
CBI-11 (Fig. 3A). We then stimulated CBI-2 once at $8-9 \mathrm{~Hz}$ for 3 min (Fig. $3 B$ ). Finally, we stimulated CBI-11 several more times (Fig. 3C) until CPG activity returned to control levels (Fig. 3D). The intertrial interval between stimulations was set to $20-50 \mathrm{~s}$. CPG activity was monitored via intracellular recordings from the radula protraction motor neuron $\mathrm{B} 61$, and the radula closing motor neuron B8. Additionally, we used extracellular recordings from the $\mathrm{I} 2$ nerve to monitor aggregate activity of protraction motor neurons B61 and B31 (Hurwitz et al., 1994). Group data show that prestimulation of CBI-2 enhanced the ability of CBI-11 to induce $\mathrm{CPG}$ activity: the average $\mathrm{B} 61$ burst frequency $\left(F_{(2,4)}=\right.$ $30.1, p<0.01, n=3$; Fig. 3G1) and frequency of full-cycle motor programs $\left(F_{(2,4)}=38.2, p<0.01, n=3\right.$; Fig. $\left.3 H 1\right)$ were higher.

Because CBI-11 does not contain the peptide CP2 that is present in CBI-2 (Fig. 2B), we sought to determine whether the effects of CBI-2 prestimulation could be mimicked by application of exogenous CP2. To accomplish this, we stimulated CBI-11 for 3 min repeatedly and tested the effects of $10^{-6} \mathrm{M} \mathrm{CP} 2(n=4$; Fig. $3 E$ ). Effects of $\mathrm{CP} 2$ were similar to those of $\mathrm{CBI}-2$ stimulation: the average B61 burst frequency $\left(F_{(2,6)}=15.8, p<0.01, n=4\right.$; Fig. $3 G 2)$ and frequency of full-cycle motor programs $\left(F_{(2,6)}=14.7\right.$, $p<0.01, n=4$; Fig. 3H2) were higher.

\section{Effects of $\mathrm{CBI}-11$ versus $\mathrm{CBI}-2 / \mathrm{CP} 2$ on the $\mathrm{CPG}$}

The enhancing effect of prior CBI-2 stimulation on CBI-11elicited programs was particularly apparent in effects exerted on protraction motor neuron B61. Therefore, we sought to determine whether CBI-11 synapses directly on B61. We found that CBI-11 elicited monosynaptic one-for-one EPSPs in B61 (Fig. $4 A$ ) that persisted in high-divalent saline (Fig. 4B). However, EPSP amplitude in normal saline was small $(<2 \mathrm{mV}$ even after a burst of CBI-11 spikes) and often did not drive B61 to spike (Fig. $4 A$ ), consistent with weak firing of B61 during CBI-11-elicited network activity (Fig. $3 A$ ). We also found that $10^{-3} \mathrm{M}$ hexamethonium blocked the EPSP from CBI-11 to B61 (Fig. 4B), suggesting that CBI-11 may be cholinergic.

The weak input from CBI-11 to B61 suggests that, under control conditions, CBI-11 is not likely to induce significant spiking in B61 (see also Fig. 3A). We hypothesized that prior CBI-2 stimulation might modify this situation by directly enhancing B61 excitability. To test this possibility, B61 excitability was measured with 3 s constant current pulses every $60 \mathrm{~s}$ before and after stimulation of CBI-2 (9 Hz, $20 \mathrm{~s})$. Our data indicate that CBI-2 stimulation significantly increases B61 excitability $\left(F_{(2,4)}=31.4, p<\right.$ $0.01, n=3$; Fig. $5 A$ ). To determine whether this effect is mediated in part by $\mathrm{CP} 2$, we applied $\mathrm{CP} 2$ to $\mathrm{B} 61$ in high-divalent saline. We found that excitability was significantly increased $\left(F_{(2,6)}=15.5\right.$, $p<0.01, n=4$; Fig. 5B).

Together, these data show that prior CBI-2 stimulation enhances the ability of CBI-11 to drive CPG activity. This effect may be at least partly mediated by the actions of $\mathrm{CP} 2$, a peptide that CBI-2 contains but CBI-11 lacks.

\section{Program specification by CBI-11 and its effects on CBI-2- driven motor programs}

Although the ability of CBI-11 to drive programs is relatively weak, we noticed that, when programs are induced in rested preparations (i.e., preparations with no stimulation for $10 \mathrm{~min}$ or longer), they are mostly ingestive. We analyzed data quantitatively from 27 animals by determining the B8 firing frequency during protraction and retraction in cycles of programs induced by CBI-11. We analyzed 96 full-cycle programs to determine whether they are ingestive, egestive, or intermediate (Fig. 6A). In addition, we analyzed 47 incomplete cycles (i.e., cycles without an obvious retraction), although they are not considered fullfeatured programs. In these latter programs, B8 activity during "retraction" is counted for a maximum of $10 \mathrm{~s}$. We plotted all data together (Fig. 6A). We found that 80 of 96 full cycle programs were ingestive, whereas 36 of 47 incomplete programs were intermediate. More importantly, no programs were egestive. These data suggest that CBI-11-elicited programs are biased toward ingestion. CBI-11 therefore differs from both CBI-2 and another command-like neuron, $\mathrm{CBI}-4$. In rested preparations, $\mathrm{CBI}-2$ and $\mathrm{CBI}-4$ can evoke both ingestive and egestive programs (Morgan et al., 2002; Jing et al., 2004).

We therefore sought to determine whether CBI-11 activity could bias CBI-2-elicited programs toward ingestion (Fig. 6B). In the example shown, direct stimulation of CBI-11 did not initially evoke any activity (Fig. 6B1). However, when CBI-11 and CBI-2 were costimulated, a full cycle was induced showing parametric features that differed from those of motor programs induced by CBI-2 stimulation alone (Fig. 6 B3 vs B2). Specifically, motor programs were more ingestive in that radula closer motor neuron $\mathrm{B} 8$ was less active during protraction $\left(F_{(2,14)}=5.89, p<0.05, n=8\right.$; Fig. $6 C)$ and more active during retraction $\left(F_{(2,14)}=15.09, p<\right.$ $0.001, n=8$; Fig. $6 C$ ). In addition, the protraction duration was longer $\left(F_{(2,14)}=12.32, p<0.001, n=8\right.$; Fig. $\left.6 D\right)$. Importantly, these effects of CBI-11 stimulation did not persist: the motor program elicited by CBI-2 alone immediately after costimulation of CBI-11 and CBI-2 was identical to the control.

Our data suggest that CBI-11 acts to bias CBI-2-elicited motor programs toward ingestive patterns. Questions remained whether CBI-11 activity is required for CBI-2 to generate ingestive patterns. To investigate this, we analyzed a subset of data in which we had dual recordings of CBI-2 and CBI-11, stimulated CBI-2 to evoke programs, and additionally recorded from B8 (data taken from 8 preparations). We divided each cycle of CBI2-elicited programs into 3 groups based on CBI-11 firing frequency: weaker than $1 \mathrm{~Hz}$ (48 cycles), between $1 \mathrm{~Hz}$ and $2.5 \mathrm{~Hz}$ (26 cycles), and stronger than $2.5 \mathrm{~Hz}$ (17 cycles), and plotted the data in Figure $6 E$. First, the data show that, when CBI-11 fired at $>2.5 \mathrm{~Hz}, 16$ of 17 cycles of CBI-2-elicited programs were ingestive. This is consistent with the idea that CBI-11 plays a role in promoting ingestive programs. However, in the absence of significant CBI-11 firing ( $<1 \mathrm{~Hz}$ ), 40 of 48 cycles of CBI-2-elicited programs were ingestive. Therefore, although CBI-11 is sufficient to convert CBI-2-elicited intermediate/weakly ingestive programs to ingestive ones, it is not necessary for CBI-2 to generate ingestive activity. Therefore, other cells, such as CBI-3 (Jing and Weiss, 2001; Morgan et al., 2002), may also contribute to the ability of CBI-2 to induce ingestive programs.

\section{Diverse actions of CBI-11 on the buccal CPG}

To determine potential mechanisms by which CBI-11 may specify ingestive programs and make CBI-2-elicited programs immediately ingestive, we first examined the direct effects of CBI-11 on B8. We found that CBI-11 elicited fast IPSPs and slow EPSPs in B8 (Fig. 7). Fast IPSPs followed presynaptic spikes one-for-one when they facilitated to be large enough to be distinguishable (Fig. $7 B$ ). Figure $7 C$ shows that a burst of CBI- 11 activity interrupted B8 spontaneous firing. Immediately after the CBI-11 burst, B8 fired at higher frequency. Because CBI-11 is normally active during protraction and weakly active or inactive during retraction, this dual-component synaptic input to B8 would promote stronger activity of B8 during retraction, an essential feature of an ingestive pattern. 
A Control

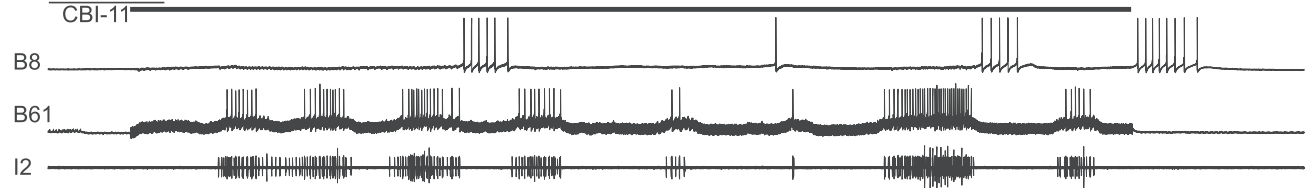

B

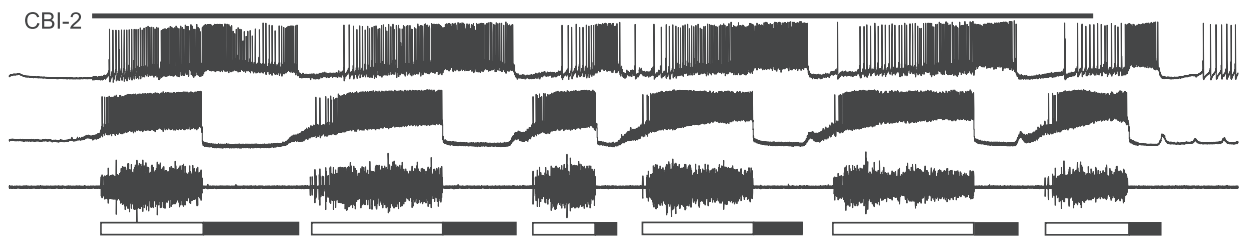

C Post $\mathrm{CBI}-2$

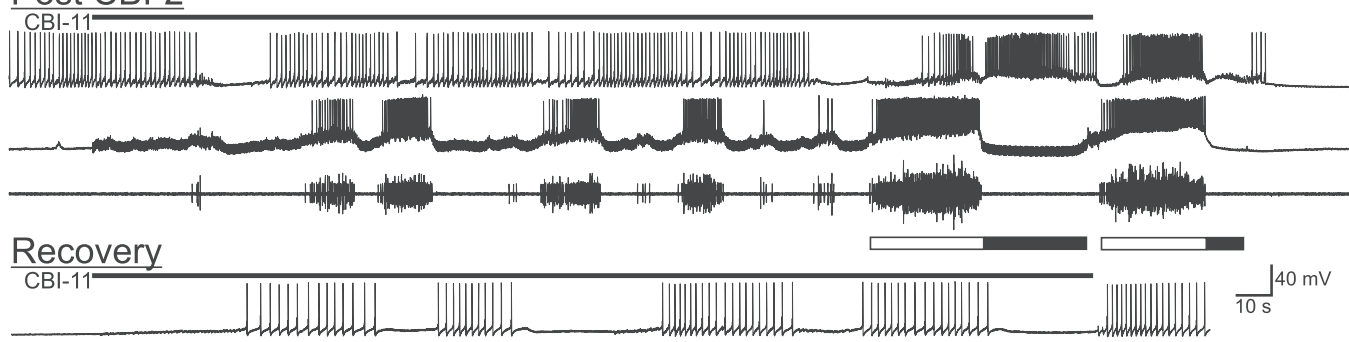

D Recovery

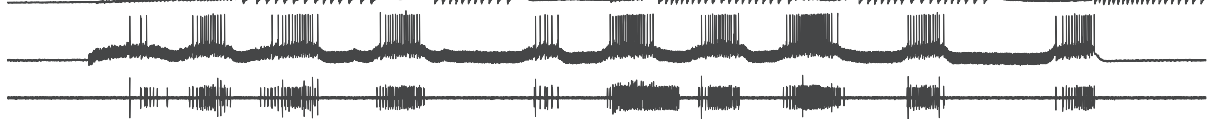

E $\quad \underline{C P} 2$

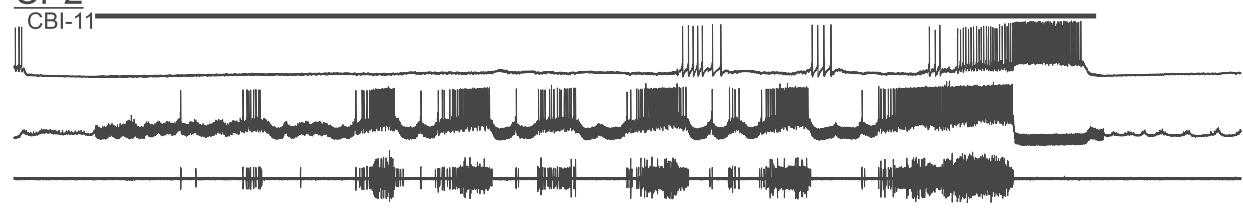

F Wash

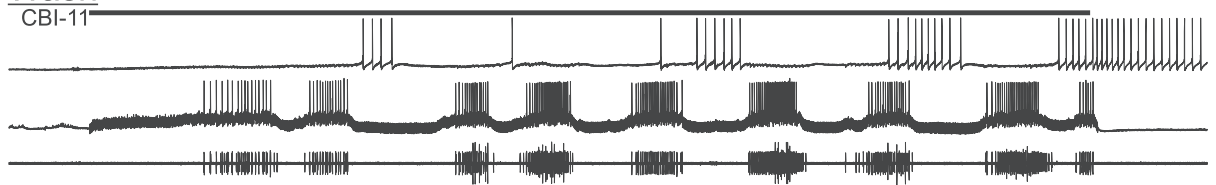

G1

G2
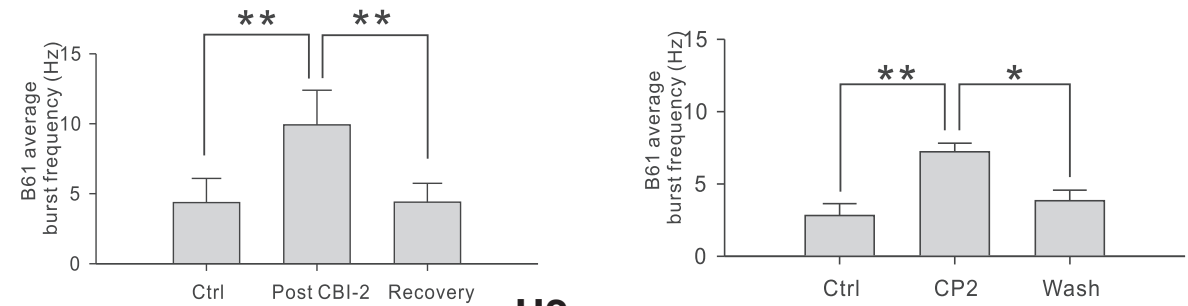

H1
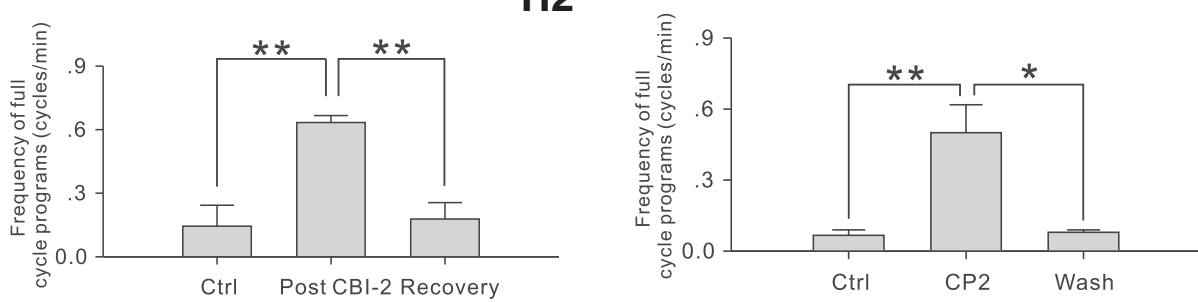

Figure 3. A, Control network activity evoked by (BI-11 stimulation ( $9 \mathrm{~Hz}$ for $3 \mathrm{~min}$ ). Prior (BI-2 stimulation ( $\boldsymbol{B}, 8 \mathrm{~Hz}$ for 3 min) enhances the ability of CBI- 11 ( $9 \mathrm{~Hz}$ for 3 min) to evoke CPG activity as reflected in the activity of the protraction motor neuron B61 (C). D, Network activity evoked by (BI-11 after C. E, CBI-2 effect is mimicked by application of exogenous (P2 (the peptide that CBI-2 contains). $\boldsymbol{F}$, Network activity evoked by (BI-11 after $\boldsymbol{E}$. G, $\boldsymbol{H}$, Group data showing effects of prior (BI-2 stimulation on B61 burst frequency (G1) and frequency of full-cycle programs ( $\boldsymbol{H} \mathbf{1})$ and effects of $\mathrm{CP} 2$ on B61 burst frequency (G2) and frequency of full-cycle programs (H2). Bonferroni post hoc tests: ${ }^{*} p<0.05$; ${ }^{* *} p<0.01$; ${ }^{* * *} p<0.001$. Error bars indicate SEM. 

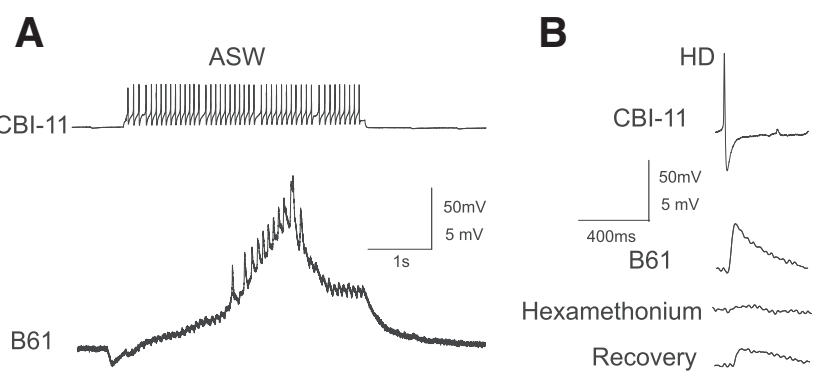

Figure 4. Weak excitatory input from $\mathrm{CBI}-11$ to $\mathrm{B} 61$. . . $\mathrm{CBI}-11$ action potentials elicited fast one-for-one EPSPs in the ipsilateral B61. $\boldsymbol{B}$, The fast EPSPs in B61 persist in a HiDi solution, suggesting that they are monosynaptic. In addition, the fast EPSP is blocked by $10^{-3} \mathrm{~m}$ hexamethonium, suggesting that $\mathrm{CBI}-11$ acts on $\mathrm{B} 61$ through the release of acetylcholine.

Next, we sought to determine whether CBI-11 acts on buccal CPG elements that are important for the expression of different types of motor programs. We first recorded from B40 (Jing and Weiss, 2002; Jing et al., 2003), an interneuron that is critical for the expression of ingestive programs, by promoting more B8 activity during retraction and less $\mathrm{B} 8$ activity during protraction. We found that CBI-11 elicited monosynaptic EPSPs on B40, which persisted in high-divalent saline (Fig. 8A). CBI-11 also enhanced B40 excitability $\left(F_{(3,6)}=34.93, p<0.001, n=3\right.$; Fig. $\left.8 B\right)$.

In addition, we examined the effects of CBI- 11 on B4/5 (Kabotyanski et al., 1998; Jing and Weiss, 2001), which inhibits B8 during retraction, thereby promoting egestive motor programs. We found that CBI-11 elicited IPSPs in B4/5 that persisted in high-divalent saline (Fig. 9A). CBI-11 also inhibited B4/5 excitability $\left(F_{(3,9)}=139.2, p<0.0001, n=4\right.$; Fig. $\left.9 B\right)$. Therefore, the actions of CBI-11 on B8, B40, and B4/5 may all promote the generation of programs of an ingestive nature.

To determine how CBI-11 may lengthen program duration, we examined the effects of CBI-11 on B64, an interneuron that terminates protraction and is critical for the initiation of retraction (Hurwitz et al., 1994; Wu et al., 2007). We found that CBI-11 elicited IPSPs in B64 that persisted in high-divalent saline, suggesting that the connection is monosynaptic (Fig. 10A). In addition, CBI-11 suppressed B64 excitability $\left(F_{(3,9)}=26.78, p<\right.$ $0.0001, n=4$; Fig. 10B). Effects of CBI-11 on B64 are consistent with the idea that CBI-11 activity promotes programs with a relatively long protraction duration.

\section{Discussion}

\section{Program activation versus specification}

Our goal was to explore how a population of command-like neurons contributes to motor program generation. Specifically, we show that different command-like neurons may function preferentially as either activators (CBI-2) or specifiers (CBI-11) of motor programs. More importantly, functional differentiation of command-like neurons allowed us to uncover complementary interactions between these two classes of neurons.

CBI-2 was one of the first command-like neurons to be identified in Aplysia (Rosen et al., 1991). A large body of work indicates that CBI-2 provides strong, fast synaptic inputs to many critical buccal CPG elements and is the most powerful activator of feeding-related motor programs (Rosen et al., 1991; Jing and Weiss, 2001; Morgan et al., 2002; Hurwitz et al., 2003). We now study CBI-11, a weak activator of programs. Similar to other multifunctional networks, the Aplysia feeding CPG produces several types of programs (ingestive, intermediate, and egestive; Morton and Chiel, 1993a). Under resting conditions, CBI-2
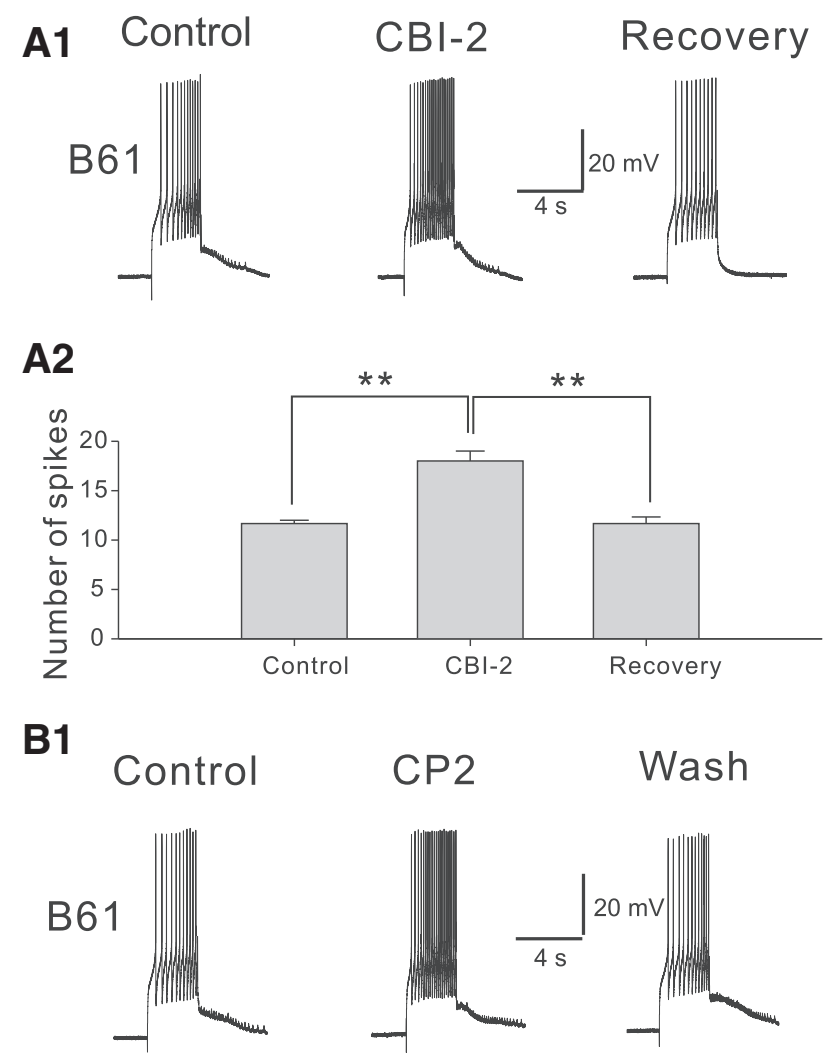

B2

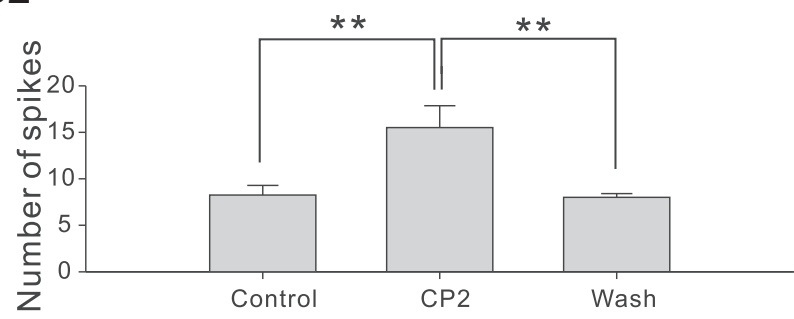

Figure 5. $\quad(B I-2$ and $C P 2$ enhances $B 61$ excitability. $A,(B I-2$ activity $(9 \mathrm{~Hz}$ for $20 \mathrm{~s}$ ) enhances B61 excitability (10 $s$ after (BI-2 stimulation). A1, Representative examples; $\boldsymbol{A 2}$, Group data $(n=3) . B\left(10^{-6}\right.$ M CP2 enhances B61 excitability. B1, Representative examples; $\boldsymbol{B} 2$, Group data $(n=4)$. All recordings were made in a high divalent saline. Bonferroni post hoc tests: ${ }^{* *} p<0.01$. Error bars indicate SEM.

(Morgan et al., 2002) and at least one other command-like neuron, CBI-4 (Jing et al., 2004), can drive different types of motor program, suggesting that their activation does not represent an immediate commitment to one type of program or another. Indeed, CBI-2 needs to be stimulated repeatedly to generate an ingestive program (Proekt et al., 2004, 2007; Friedman and Weiss, 2010). Here, we found that CBI-11 differs from both CBI-2 and CBI-4 in that, although it is weak in activating programs, programs are mostly ingestive when it is successful. These results support the notion that, in rested preparations, CBI-2 may function primarily as an activator of programs, whereas CBI-11 acts primarily as a specifier of the type of programs articulated. Importantly, the program-specifying action of CBI-11 is immediate. In contrast, the programspecifying action of CBI-2 is dynamic because it depends on the history of its activity.

Why does the feeding network need at least two distinct classes of command-like neurons to produce motor programs? The an- 
A

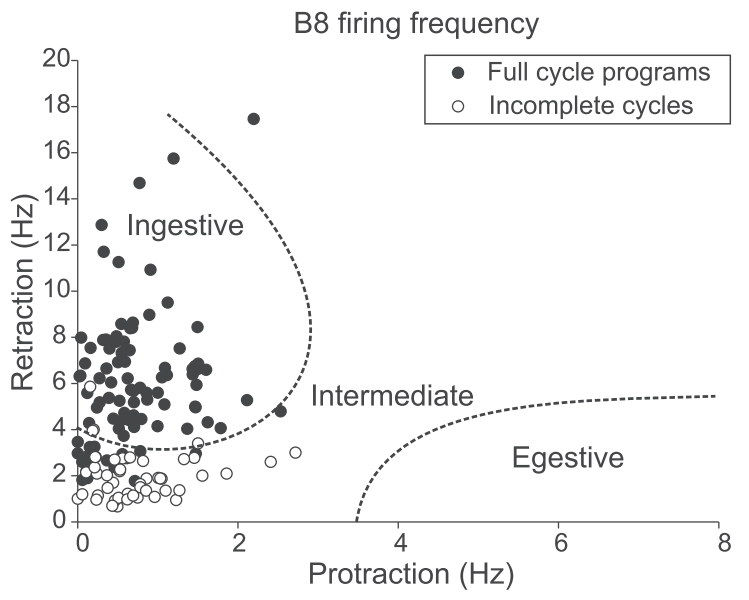

B

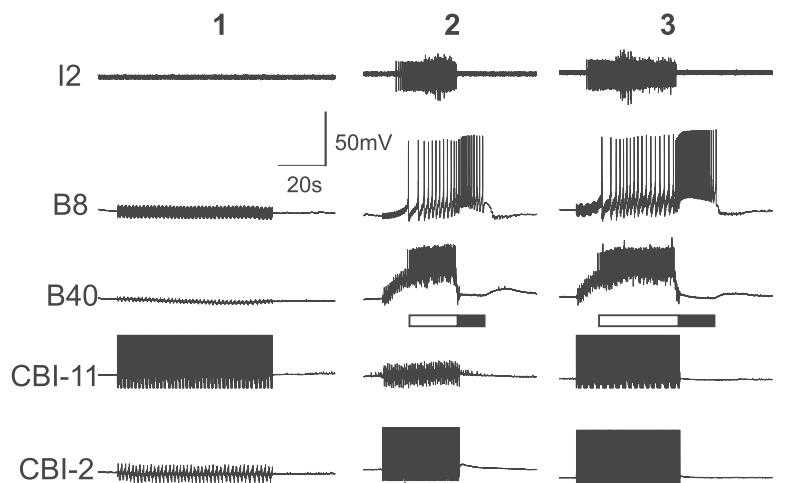

C

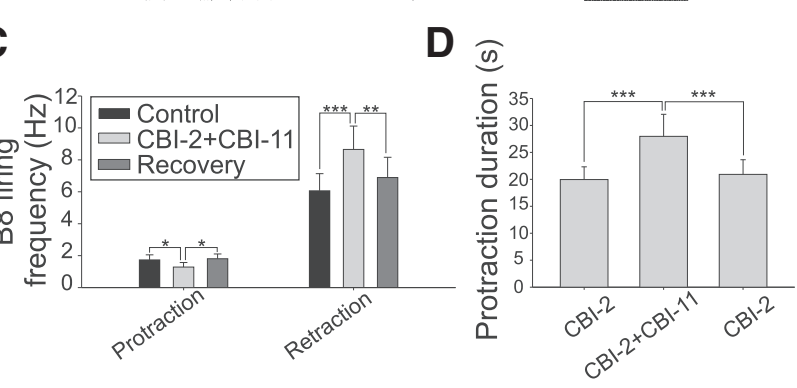

E

B8 firing frequency

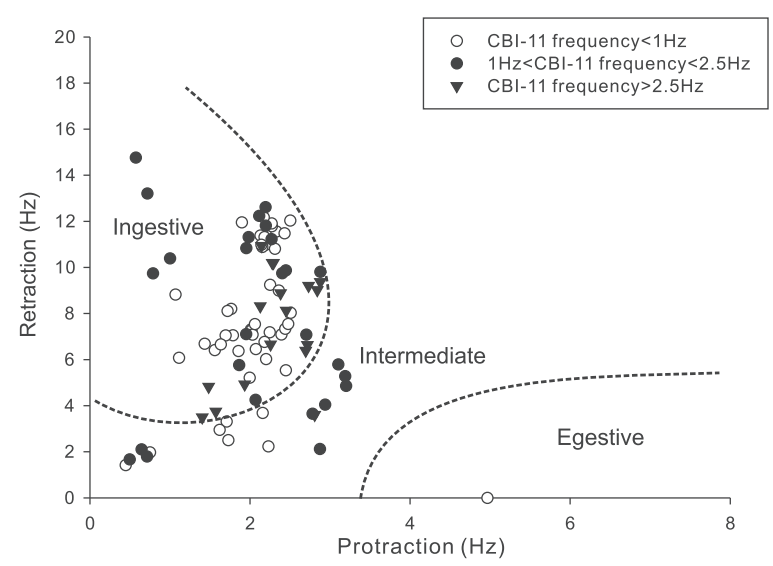

Figure 6. $\quad$ (BI-11 promotes ingestive motor programs elicited by $\mathrm{CBI}-2$, but is not required for $\mathrm{CBI}-2$ to evoke ingestive programs. $A$, Motor programs elicited by CBI-11. Most full-cycle programs were ingestive, whereas incomplete cycles of programs were intermediate. Dotted lines indicate ingestive and egestive clusters as described previously (Morgan et al., 2002, Jing et al., 2004). B1, (BI-11 at $7 \mathrm{~Hz}$ does not trigger a motor program (Note the absence of activity in 12 and B8). B2, (BI-2 stimulation elicited an intermediate motor program in which B8 was
A
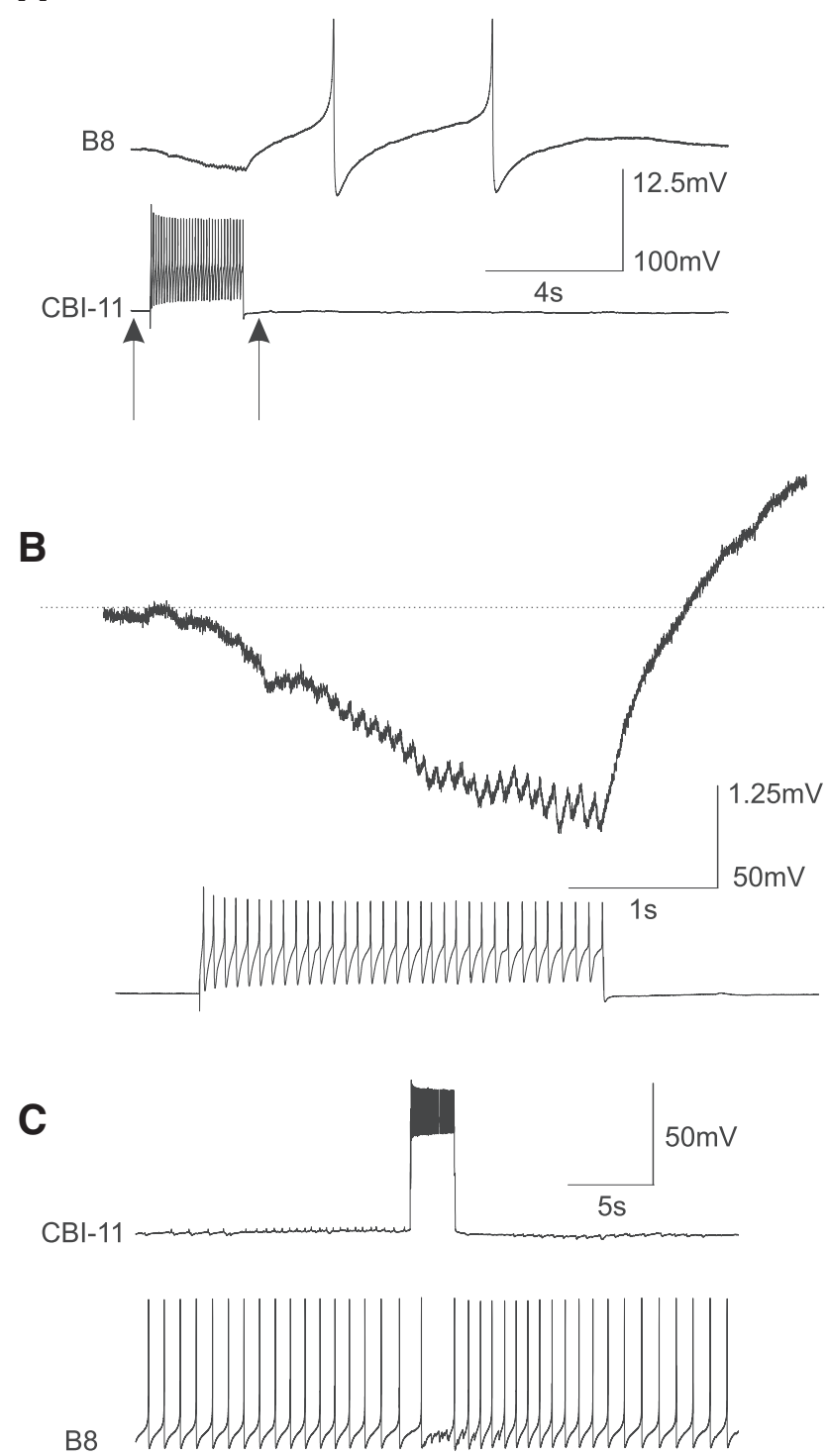

Figure 7. CBI-11 produces fast IPSPs and slow EPSPs in B8. $A$, CBI-11 firing elicits hyperpolarizing synaptic potentials in B8. $\boldsymbol{B}$, An expanded view showing fast and slow IPSPs in B8. C, Stimulation of $\mathrm{CBI}-11$ decreases $\mathrm{B} 8$ firing. $\mathrm{B} 8$ firing is higher after termination of $\mathrm{CBI}-11$ stimulation.

swer emerges from experiments aimed at examining how the two neurons differ and how they interact to produce motor programs. The powerful actions of CBI-2 have been attributed to the strong modulatory-and largely excitatory-actions of its two neuropeptides, FCAP and CP2 (Koh et al., 2003; Friedman and Weiss, 2010). FCAP and CP2 have been thought to act as a unit

weakly active during both protraction and retraction. B3, Costimulation of CBI-2 and CBI-11 results in increased $B 8$ firing during retraction and an increase in protraction duration. $C$, Group data showing changes in $\mathrm{B} 8$ firing frequency during protraction and retraction in $\mathrm{CBI}-2$-elicited motor programs upon stimulation of CBI-11 $(n=8)$. Bonferroni post hoc tests: ${ }^{*} p<0.05$; ${ }^{* * *} p<0.001$. Error bars indicate SEM. $\boldsymbol{D}$. Group data show a statistically significant increase in the duration of the protraction phase of $\mathrm{CBI}-2$-elicited motor programs upon costimulation of CBI-11 $(n=8)$. $\boldsymbol{E}$, Motor programs elicited by $\mathrm{CBI}-2$, with simultaneous recordings of CBI-11. Programs are divided into three groups based on $\mathrm{CBI}-11$ firing frequency recruited by $\mathrm{CBI}-2$ stimulation. When $\mathrm{CBI}-11$ frequency is $>2.5 \mathrm{~Hz}, 16$ of 17 programs are ingestive. Conversely, when the $\mathrm{CBI}-11$ frequency is $<1 \mathrm{~Hz}$, 40 of $48 \mathrm{CBI}-2$-elicited programs are ingestive. 


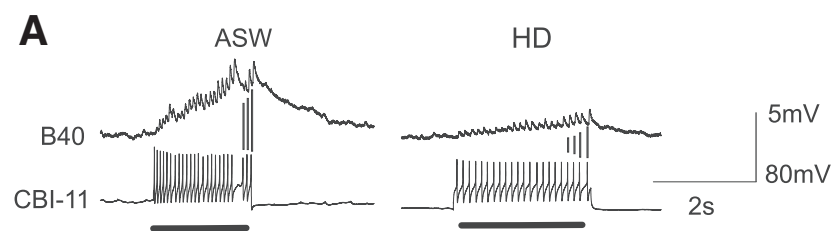

B1

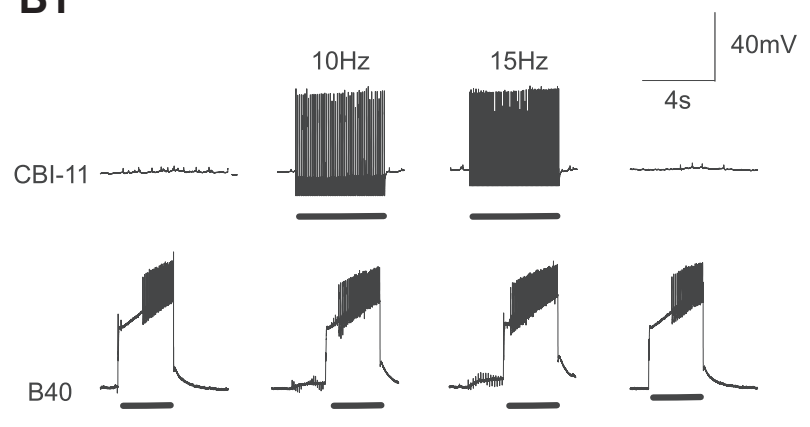

B2

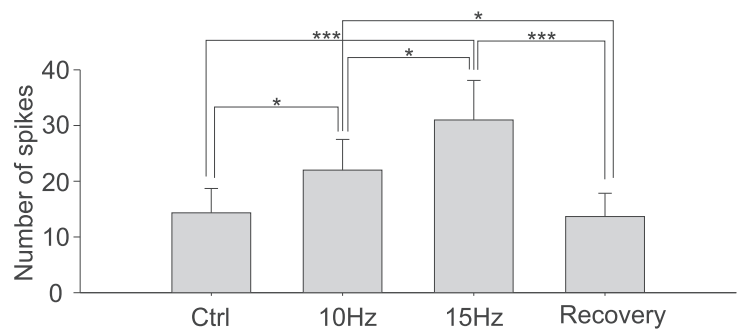

Figure 8. CBI-11 excites B40. A, CBI-11 action potentials elicit fast one-for-one EPSPs in the ipsilateral $B 40$. The fast EPSPs in B40 persist in a HiDi solution, suggesting that they are monosynaptic. B1, CBI-11 increases B40 excitability in a frequency-dependent manner. B2, Group data $(n=3)$. Bonferroni post hoc tests: ${ }^{*} p<0.05$; ${ }^{* * *} p<0.001$. Error bars indicate SEM.

because both enhance program generation. We therefore examined the possibility that the difference in the ability of CBI-2 and CBI-11 to evoke programs may originate at least in part from a difference in the peptide content of the two CBIs. Indeed, although CBI-11 contains FCAP, as does CBI-2, CBI-11 lacks CP2, providing a partial explanation for why CBI-11 drives programs less reliably than CBI-2. Furthermore, a 3 min prestimulation of CBI-2, which releases CP2 (Koh and Weiss, 2005), can enhance the ability of subsequent CBI-11 stimulation to drive motor output (including activity in B61). Importantly, this effect is mimicked by $\mathrm{CP} 2$, and both CBI-2 activity and $\mathrm{CP} 2$ can directly enhance B61 excitability (Fig. 11A). Therefore, our data suggest that CBI-2 can exert persistent, probably peptide-mediated actions that promote the ability of CBI-11 alone to induce motor programs. We note that our work primarily studied motor patterns rather than behavior. Although our experiments uncovered modulatory actions of CBI-2, we do not yet know of any circumstances in which CBI-11 is activated alone. We speculate that this may occur during ingestion of different types of food.

Next, we tested the converse possibility that CBI-11 affects CBI-2-elicited motor programs. We found that, when CBI-11 is coactivated with CBI-2, CBI-2-elicited programs immediately become ingestive. Protraction duration also becomes longer. Our study indicates that these effects of CBI-11 are implemented in part by its ability to enhance the activity of the ingestionpromoting CPG element B40 and suppress the activity of the protraction terminator B64 (Fig. 11B). Therefore, the program-
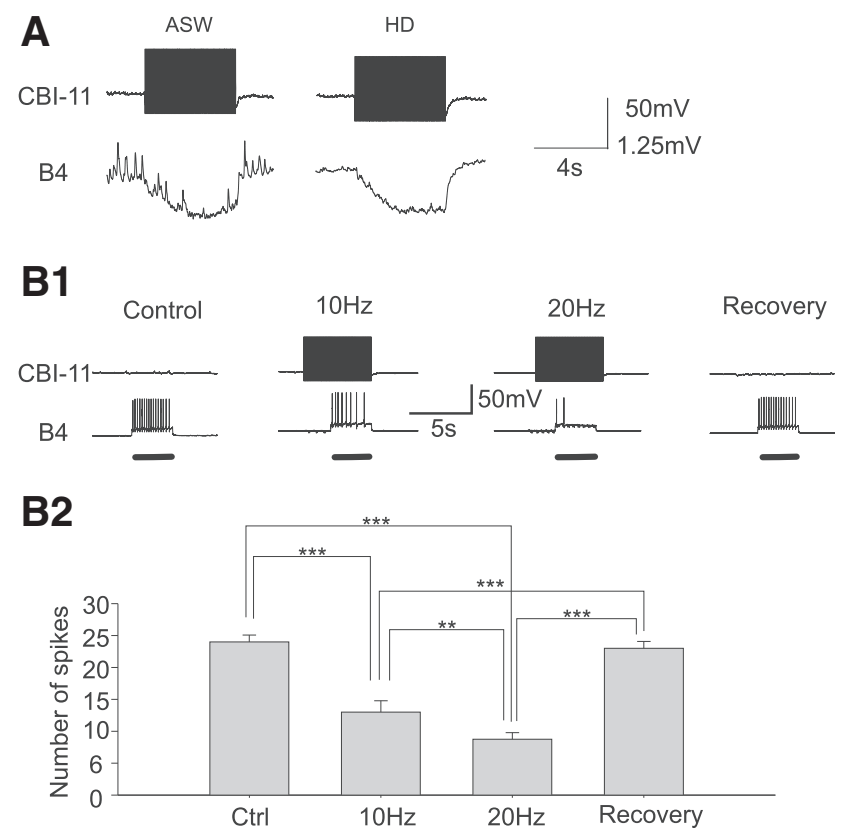

Figure 9. CBI-11 activity hyperpolarizes B4. A, CBI-11 elicits hyperpolarizing synaptic potentials in $B 4$, which persists in a HiDi solution, suggesting that they are monosynaptic. B1, CBI-11 decreases B4 excitability of in a frequency-dependent manner. B2, Group data $(n=4)$. Bonferroni post hoc tests: ${ }^{* *} p<0.01 ;{ }^{* * *} p<0.001$. Error bars indicate SEM.
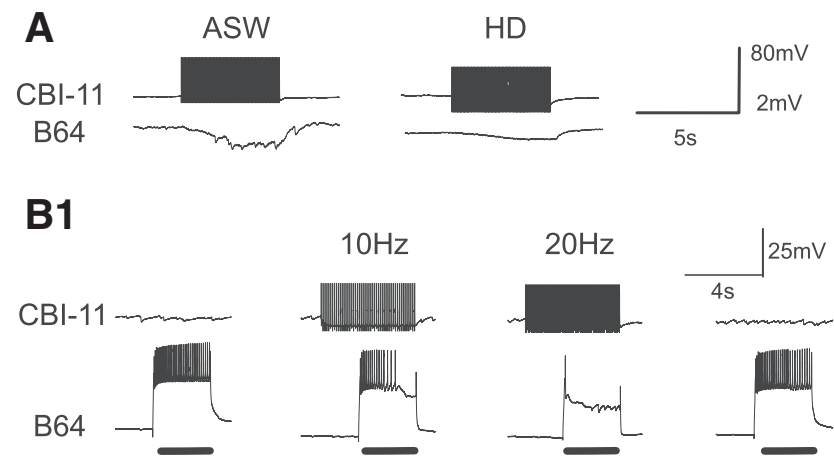

\section{B2}

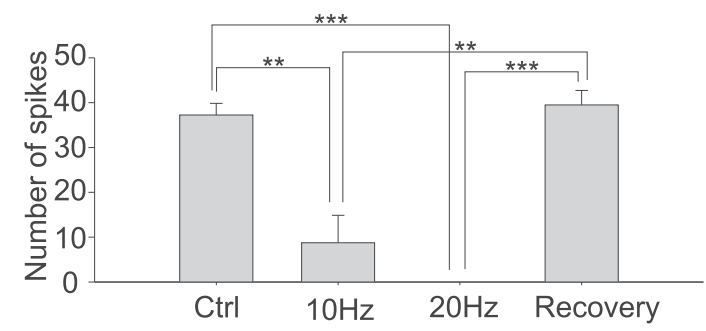

Figure 10. CBI-11 elicits slow hyperpolarization in B64. A. CBI-11-elicited IPSPs in B64 persist in a high-divalent saline. $B$ 1, CBI-11 reduces B64 excitability in a frequency-dependent manner. B2. Group data $(n=4)$. Bonferroni post hoc tests: ${ }^{* *} p<0.01$; ${ }^{* * *} p<0.001$. Error bars indicate SEM.

specifying function of CBI-11 complements the actions of CBI-2 by making CBI-2-elicited programs immediately ingestive, thus rendering the slow dynamics unnecessary.

\section{Functional classification of interneurons}

One lesson that can be drawn from this work is that the model system approach can be very effective at revealing mechanistic nuances that are difficult to uncover in more complex systems. 

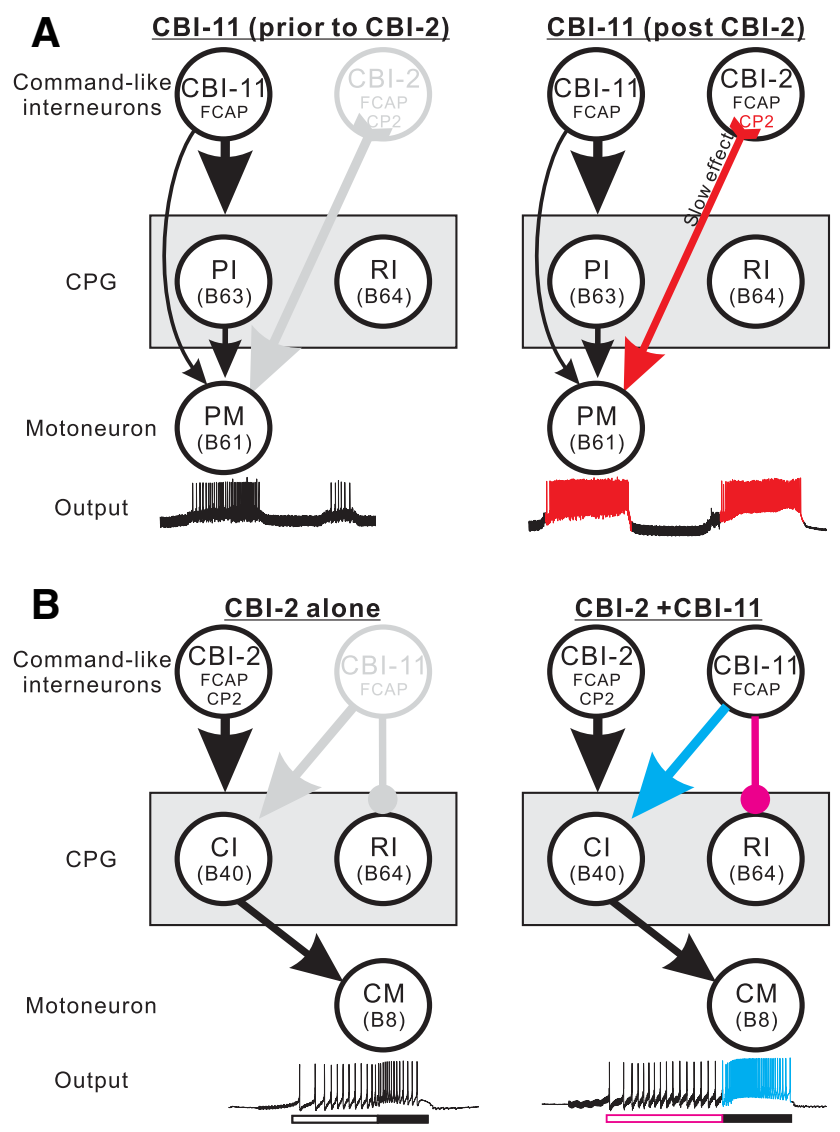

C

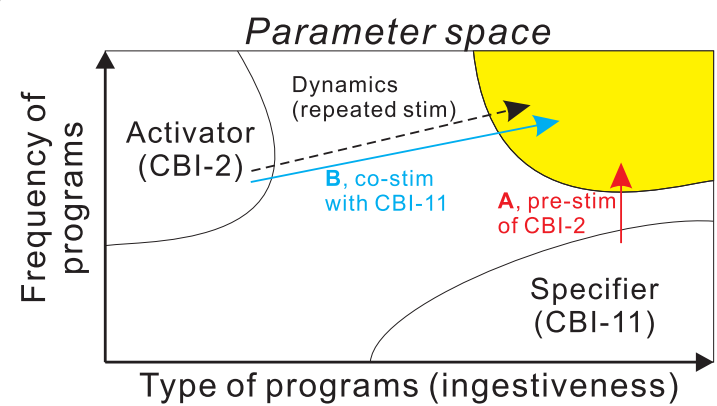

Figure 11. Schematic diagram of temporally distinct interactions between command-like interneurons $\mathrm{CBI}-2$ and $\mathrm{CBI}-11$. A, $\mathrm{CBI}-2$ effects on $\mathrm{CBI}-11-$ elicited programs. Under control condition (left) $\mathrm{CBI}-11$ activation elicits weak activity in the $\mathrm{CPG}$, as expressed in the activity of protraction motor neuron (PM) B61. However, after prior (BI-2 stimulation (right), the CP2 that is present in $\mathrm{CBI}-2$ has a persistent enhancing effect on $\mathrm{B} 61$ excitability, which allows $\mathrm{CBI}-11$ to elicit strong CPG activity (red). PI, Protraction interneuron; RI, retraction interneuron. B, CBI-11 effects on CBI-2-elicited programs. When only $\mathrm{CBI}-2$ is stimulated (left), the ingestive nature of the programs is weak, as expressed as a closure motor neuron (CM): B8 activity during retraction (filled bar) and a relatively short protraction phase (open bar). When both (BI-2 and (BI-11 are activated (right), (BI-11 promotes closure interneuron (Cl): B40 activity and suppresses Rl: B64 activity, thereby making programs more ingestive (blue). Protraction duration is also increased (purple). Arrows, Excitatory; circles, inhibitory. C, Parameter space illustrating the frequency of programs versus their ingestiveness. When activity in $\mathrm{CBI}-2$ and $\mathrm{CBI}-11$ is combined, a larger parameter space is covered. High-frequency ingestive programs can be achieved in multiple ways, such as repeated stimulation of $(\mathrm{BI}-2$ (previous work) and combined activation of $\mathrm{CBI}-2$ and $(\mathrm{BI}-11$ (prestimulation of $\mathrm{CBI}-2 ; \boldsymbol{A}$; costimulation of $(\mathrm{BI}-11$ with $(\mathrm{BI}-2 ; \boldsymbol{B})$. Stim, Stimulation.

For example, CBI-2 and CBI-11 are similar in that both are peptidergic command-like neurons, are electrically coupled, and have similar activity patterns during feeding (Jing and Weiss, 2005; Fig. 1B). This similarity might imply that the two neurons function as one unit. However, the experimentally advantageous features of the Aplysia feeding network enabled us to perform mechanistic analyses that identified functional differences between the two neurons. Specifically, we found that the two command-like neurons differ importantly in that one functions preferentially, but not exclusively, as an activator and the other as a specifier of network output. In addition, we characterized novel, complementary interactions that contribute to motor program generation and specification. Moreover, we showed that the difference in the ease with which the two command-like neurons drive programs may be attributable to their different peptide complements.

The peptidergic mechanisms revealed here may have implications for approaches to functionally classify interneurons, particularly projection neurons in other systems. Many projection neurons are peptidergic. This is the case in many model systems (Blitz et al., 1999; Morgan et al., 2002; Nusbaum and Beenhakker, 2002) and in regions of the mammalian brain such as the brainstem, striatum, and hypothalamus (Kandel et al., 2000). In these more complex circuits, many interneurons contain more than one peptide (McBain and Fisahn, 2001; Klausberger and Somogyi, 2008) and, similar to CBIs in Aplysia, it is likely that these neurons may also contain partially overlapping sets of peptides. Therefore, our findings provide novel insights that may be used to characterize peptidergic functions, to classify interneurons, and ultimately to understand network functioning in more complex animals.

\section{Neural coding}

Work in a number of model systems has shown that both sensory features and motor parameters are commonly encoded by populations of neurons (Georgopoulos et al., 1986; Lee et al., 1988; Lewis and Kristan, 1998; Pouget et al., 2000; Nicolelis, 2001). It is instructive to consider neural coding on more than one level. For example, the Aplysia feeding circuit is composed of at least two levels: pattern-generating neurons in the buccal ganglia and command-like neurons in the cerebral ganglion. Overall, current evidence supports the notion that population coding is used at both levels. However, each level likely encodes something different. Namely, pattern-generating neurons encode low-level movement parameters of a behavior using both behavior-specific and behavior-independent modules (Jing et al., 2004). In contrast, command-like neurons drive and thus encode a whole sequence of movements; that is, a behavior.

Despite the progress that has been made in understanding command neuron functions, it is still not completely resolved whether individual neurons within a single network encode one type of behavior or multiple types. Earlier work in the mollusk Pleurobranchaea suggested that each command neuron drives a single type of motor pattern (Croll et al., 1985). However, pattern-generating elements that are activated by command neurons in this system still await a detailed characterization. Therefore, this finding remained to be verified. In contrast, more recent work in Aplysia suggests that command-like neurons such as CBI-2 (Jing and Weiss, 2001; Morgan et al., 2002) and CBI-4 (Jing et al., 2004) drive more than one type of program, which is consistent with findings on command-like neurons in the cricket and leech (Nolen and Hoy, 1984; Esch et al., 2002). Furthermore, work in Aplysia showed that population coding helps specify the type of program expressed. For example, CBI-3, a higher-order interneuron that does not drive programs and therefore is not a command neuron, can convert CBI-2-elicited egestive programs into ingestive ones (Jing and Weiss, 2001; Morgan et al., 2002). 
Here, we found that the command-like neuron CBI-11 acts as a specifier of programs because it primarily elicits ingestive programs and does not drive egestive programs, which is more consistent with the findings in Pleurobranchaea. Combined with previous work in Aplysia, the present study indicates for the first time that, within one network, command-like neurons differ in their specificity with respect to program specification.

More generally, Aplysia findings demonstrate a network organization in which a variety of command-like neurons exist: some function primarily as activators of multiple behaviors, whereas others act like specifiers. To specify a behavior at any given moment, different combinations of neurons that exert differing levels of program activating and specifying influences may be used. This population coding scheme is highly flexible, because network activity patterns driven by a population of command-like neurons may cover a larger parameter space than that which can be covered by single neurons and thus allow a specific type of program to be generated in multiple ways (Fig. 11C). Given that activation of neurons in the motor cortex of monkeys can also evoke distinct outputs and behaviors (Graziano et al., 2002; Overduin et al., 2012), we expect that the coding scheme in Aplysia may be applicable to other systems, including vertebrates.

\section{References}

Benjamin PR (2012) Distributed network organization underlying feeding behavior in the mollusk Lymnaea. Neural Syst Circuits 2:4. CrossRef Medline

Blitz DM, Christie AE, Coleman MJ, Norris BJ, Marder E, Nusbaum MP (1999) Different proctolin neurons elicit distinct motor patterns from a multifunctional neuronal network. J Neurosci 19:5449-5463. Medline

Briggman KL, Kristan WB (2008) Multifunctional pattern-generating circuits. Annu Rev Neurosci 31:271-294. CrossRef Medline

Church PJ, Lloyd PE (1994) Activity of multiple identified motor neurons recorded intracellularly during evoked feedinglike motor programs in Aplysia. J Neurophysiol 72:1794-1809. Medline

Croll RP, Kovac MP, Davis WJ, Matera EM (1985) Neural mechanisms of motor program switching in the mollusc Pleurobranchaea. III. Role of the paracerebral neurons and other identified brain neurons. J Neurosci 5:64-71. Medline

Dacks AM, Siniscalchi MJ, Weiss KR (2012) Removal of default stateassociated inhibition during repetition priming improves response articulation. J Neurosci 32:17740-17752. CrossRef Medline

Eaton RC, Lee RK, Foreman MB (2001) The Mauthner cell and other identified neurons of the brainstem escape network of fish. Prog Neurobiol 63:467-485. CrossRef Medline

Edwards DH, Heitler WJ, Krasne FB (1999) Fifty years of a command neuron: the neurobiology of escape behavior in the crayfish. Trends Neurosci 22:153-161. CrossRef Medline

Esch T, Mesce KA, Kristan WB (2002) Evidence for sequential decision making in the medicinal leech. J Neurosci 22:11045-11054. Medline

Flood TF, Iguchi S, Gorczyca M, White B, Ito K, Yoshihara M (2013) A single pair of interneurons commands the Drosophila feeding motor program. Nature 499:83-87. CrossRef Medline

Friedman AK, Weiss KR (2010) Repetition priming of motoneuronal activity in a small motor network: intercellular and intracellular signaling. J Neurosci 30:8906-8919. CrossRef Medline

Frost WN, Katz PS (1996) Single neuron control over a complex motor program. Proc Natl Acad Sci U S A 93:422-426. CrossRef Medline

Furukawa Y, Nakamaru K, Wakayama H, Fujisawa Y, Minakata H, Ohta S, Morishita F, Matsushima O, Li L, Romanova E, Sweedler JV, Park JH, Romero A, Cropper EC, Dembrow NC, Jing J, Weiss KR, Vilim FS (2001) The enterins: a novel family of neuropeptides isolated from the enteric nervous system and CNS of Aplysia. J Neurosci 21:8247-8261. Medline

Georgopoulos AP, Schwartz AB, Kettner RE (1986) Neuronal population coding of movement direction. Science 233:1416-1419. CrossRef Medline

Gillette R, Kovac MP, Davis WJ (1978) Command neurons in Pleurobranchaea receive synaptic feedback from the motor network they excite. Science 199:798-801. CrossRef Medline
Graziano MS, Taylor CS, Moore T (2002) Complex movements evoked by microstimulation of precentral cortex. Neuron 34:841-851. CrossRef Medline

Hurwitz I, Susswein AJ (1996) B64, a newly identified central pattern generator element producing a phase switch from protraction to retraction in buccal motor programs of Aplysia californica. J Neurophysiol 75:13271344. Medline

Hurwitz I, Goldstein RS, Susswein AJ (1994) Compartmentalization of pattern-initiation and motor functions in the B31 and B32 neurons of the buccal ganglia of Aplysia californica. J Neurophysiol 71:1514-1527. Medline

Hurwitz I, Kupfermann I, Susswein AJ (1997) Different roles of neurons B63 and B34 that are active during the protraction phase of buccal motor programs in Aplysia californica. J Neurophysiol 78:1305-1319. Medline

Hurwitz I, Kupfermann I, Weiss KR (2003) Fast synaptic connections from CBIs to pattern-generating neurons in Aplysia: initiation and modification of motor programs. J Neurophysiol 89:2120-2136. Medline

Jing J (2009) Command systems. In: Encyclopedia of Neuroscience, volume 2 (Squire LR, ed), pp 1149-1158. Oxford, UK: Academic.

Jing J, Gillette R (1999) Central pattern generator for escape swimming in the notaspid sea slug Pleurobranchaea californica. J Neurophysiol 81:654667. Medline

Jing J, Weiss KR (2001) Neural mechanisms of motor program switching in Aplysia. J Neurosci 21:7349-7362. Medline

Jing J, Weiss KR (2002) Interneuronal basis of the generation of related but distinct motor programs in Aplysia: implications for current neuronal models of vertebrate intralimb coordination. J Neurosci 22:6228-6238. Medline

Jing J, Weiss KR (2005) Generation of variants of a motor act in a modular and hierarchical motor network. Curr Biol 15:1712-1721. CrossRef Medline

Jing J, Vilim FS, Wu JS, Park JH, Weiss KR (2003) Concerted GABAergic actions of Aplysia feeding interneurons in motor program specification. J Neurosci 23:5283-5294. Medline

Jing J, Cropper EC, Hurwitz I, Weiss KR (2004) The construction of movement with behavior-specific and behavior-independent modules. J Neurosci 24:6315-6325. CrossRef Medline

Jing J, Sweedler JV, Cropper EC, Alexeeva V, Park JH, Romanova EV, Xie F, Dembrow NC, Ludwar BC, Weiss KR, Vilim FS (2010) Feedforward compensation mediated by the central and peripheral actions of a single neuropeptide discovered using representational difference analysis. J Neurosci 30:16545-16558. CrossRef Medline

Kabotyanski EA, Baxter DA, Byrne JH (1998) Identification and characterization of catecholaminergic neuron B65, which initiates and modifies patterned activity in the buccal ganglia of Aplysia. J Neurophysiol 79:605621. Medline

Kandel ER, Schwartz JH, Jessell TM, eds (2000) Principles of Neural Science. New York: McGraw-Hill.

Klausberger T, Somogyi P (2008) Neuronal diversity and temporal dynamics: the unity of hippocampal circuit operations. Science 321:53-57. CrossRef Medline

Koh HY, Weiss KR (2005) Peptidergic contribution to posttetanic potentiation at a central synapse of Aplysia. J Neurophysiol 94:1281-1286. CrossRef Medline

Koh HY, Vilim FS, Jing J, Weiss KR (2003) Two neuropeptides colocalized in a command-like neuron use distinct mechanisms to enhance its fast synaptic connection. J Neurophysiol 90:2074-2079. CrossRef Medline

Korn H, Faber DS (2005) The Mauthner cell half a century later: a neurobiological model for decision-making? Neuron 47:13-28. CrossRef Medline

Kupfermann I, Weiss KR (1978) The command neuron concept. Behav Brain Sci 1:3-39. CrossRef

Lee C, Rohrer WH, Sparks DL (1988) Population coding of saccadic eye movements by neurons in the superior colliculus. Nature 332:357-360. CrossRef Medline

Lewis JE, Kristan WB Jr (1998) A neuronal network for computing population vectors in the leech. Nature 391:76-79. CrossRef Medline

Marder E, Bucher D (2007) Understanding circuit dynamics using the stomatogastric nervous system of lobsters and crabs. Annu Rev Physiol 69: 291-316. CrossRef Medline

McBain CJ, Fisahn A (2001) Interneurons unbound. Nat Rev Neurosci 2:11-23. Medline

Morgan PT, Perrins R, Lloyd PE, Weiss KR (2000) Intrinsic and extrinsic 
modulation of a single central pattern generating circuit. J Neurophysiol 84:1186-1193. Medline

Morgan PT, Jing J, Vilim FS, Weiss KR (2002) Interneuronal and peptidergic control of motor pattern switching in Aplysia. J Neurophysiol 87:4961. Medline

Morton DW, Chiel HJ (1993a) The timing of activity in motor neurons that produce radula movements distinguishes ingestion from rejection in Aplysia. J Comp Physiol A 173:519-536. Medline

Morton DW, Chiel HJ (1993b) In vivo buccal nerve activity that distinguishes ingestion from rejection can be used to predict behavioral transitions in Aplysia. J Comp Physiol A 172:17-32. CrossRef Medline

Nargeot R, Baxter DA, Byrne JH (1997) Contingent-dependent enhancement of rhythmic motor patterns: an in vitro analog of operant conditioning. J Neurosci 17:8093-8105. Medline

Nicolelis MAL, ed (2001) Advances in neural population coding. Amsterdam: Elsevier.

Nolen TG, Hoy RR (1984) Initiation of behavior by single neurons: the role of behavioral context. Science 226:992-994. CrossRef Medline

Nusbaum MP, Beenhakker MP (2002) A small-systems approach to motor pattern generation. Nature 417:343-350. CrossRef Medline

Overduin SA, d'Avella A, Carmena JM, Bizzi E (2012) Microstimulation activates a handful of muscle synergies. Neuron 76:1071-1077. CrossRef Medline

Phares GA, Lloyd PE (1996) Immunocytological and biochemical localization and biological activity of the newly sequenced cerebral peptide 2 in Aplysia. J Neurosci 16:7841-7852. Medline

Pouget A, Dayan P, Zemel R (2000) Information processing with population codes. Nat Rev Neurosci 1:125-132. CrossRef Medline

Proekt A, Brezina V, Weiss KR (2004) Dynamical basis of intentions and expectations in a simple neuronal network. Proc Natl Acad Sci U S A 101:9447-9452. CrossRef Medline

Proekt A, Jing J, Weiss KR (2007) Multiple contributions of an input- representing neuron to the dynamics of the Aplysia feeding network. J Neurophysiol 97:3046-3056. CrossRef Medline

Rosen SC, Teyke T, Miller MW, Weiss KR, Kupfermann I (1991) Identification and characterization of cerebral-to-buccal interneurons implicated in the control of motor programs associated with feeding in Aplysia. J Neurosci 11:3630-3655. Medline

Sasaki K, Brezina V, Weiss KR, Jing J (2009) Distinct inhibitory neurons exert temporally specific control over activity of a motoneuron receiving concurrent excitation and inhibition. J Neurosci 29:11732-11744. CrossRef Medline

Sweedler JV, Li L, Rubakhin SS, Alexeeva V, Dembrow NC, Dowling O, Jing J, Weiss KR, Vilim FS (2002) Identification and characterization of the feeding circuit-activating peptides, a novel neuropeptide family of Aplysia. J Neurosci 22:7797-7808. Medline

Wiersma CA, Ikeda K (1964) Interneurons commanding swimmeret movements in the crayfish, Procambarus clarki (Girard). Comp Biochem Physiol 12:509-525. CrossRef Medline

Wu JS, Jing J, Díaz-Ríos M, Miller MW, Kupfermann I, Weiss KR (2003) Identification of a GABA-containing cerebral-buccal interneuron-11 in Aplysia californica. Neurosci Lett 341:5-8. CrossRef Medline

Wu JS, Due MR, Sasaki K, Proekt A, Jing J, Weiss KR (2007) State dependence of spike timing and neuronal function in a motor pattern generating network. J Neurosci 27:10818-10831. CrossRef Medline

Wu JS, Vilim FS, Hatcher NG, Due MR, Sweedler JV, Weiss KR, Jing J (2010) Composite modulatory feedforward loop contributes to the establishment of a network state. J Neurophysiol 103:2174-2184. CrossRef Medline

Xin Y, Hurwitz I, Perrins R, Evans CG, Alexeeva V, Weiss KR, Kupfermann I (1999) Actions of a pair of identified cerebral-buccal interneurons (CBI8/9) in Aplysia that contain the peptide myomodulin. J Neurophysiol 81:507-520. Medline 